\title{
EDUCAÇÃO ESCOLAR DIFERENCIADA, FORMAÇÃO DE PROFESSORES INDÍGENAS E CURRÍCULO
}

\author{
DIFFERENTIATED SCHOOL EDUCATION, TRAINING OF \\ INDIGENOUS TEACHERS AND CURRICULUM
}

\author{
Alcioni da Silva Monteiro \\ Mestre em Ensino de Ciências e Humanidades \\ pela Universidade Federal do Amazonas - UFAM; \\ Lábrea, Amazonas - Brasil. \\ alcionimonteiro@hotmail.com
}

Suely Aparecida do Nascimento Mascarenhas

Doutora em Diagnóstico e avaliação educativa-psicopedagogia pela Universidade da Coruña (2004, revalidado e registrado pela UNB);

Humaitá, Amazonas - Brasil. suelymascarenhas2019@gmail.com

Resumo: O presente artigo é uma abordagem bibliográfica que compreende os processos históricos que permitiram aos índios, o acesso à educação escolar e à formação para o educador índio. Para tal, objetivou-se a análise acerca da educação escolar diferenciada, formação de professores e currículo. A educação escolar diferenciada no Brasil tem sido tema sobre o qual pesquisadores de diversas áreas do conhecimento debruçam-se com o intuito de entendê-la, de modo a vislumbrar um modelo pedagógico que atenda às especificidades dos grupos indígenas e à formação de professores indígenas, para as possibilidades de gerenciar uma educação escolar que respeite os interesses dos povos originários, assim como, uma proposta curricular voltada as necessidades pedagógicas diferenciada, culturais e políticos, a fim de vitalizar e revitalizar a identidade indígena. Os debates em torno dos referenciais teóricos consultados como Ghedin (2007), Grupioni (2000), Peréz Ruiz (2011), Urquiza (2017) entre outros, possibilitaram conhecer os principais desafios da realidade da educação escolar indígena. Neste sentido, pretende-se provocar uma reflexão sobre a efetivação do ensino intercultural, e sobre a necessidade de formações continuadas, para a consolidação e fortalecimento da identidade do povo tradicional, na construção do currículo específico e intercultural.

Palavras-Chave: Educação escolar diferenciada. Formação de professores indígenas. Currículo.

Abstract: This article is a bibliographic approach that main understand the historical processes that allowed to the Indians, the access to school education and training for the Indian educator. The objective was to analyze differentiated school education, teacher training and curriculum. Differentiated school education in Brazil has been a theme that researchers from different areas of knowledge have been working on, in order to understand it, looking for a pedagogical model that meets the specificities of indigenous groups. With this, the training of indigenous teachers is guided as a possibility to manage a school education that meets the interests of the original people, as well as a curricular proposal aimed at pedagogical, cultural and political interests, in order to vitalize and revitalize the indigenous identity. The debates around the theoretical references consulted as Ghedin (2007), Grupioni (2000), Peréz Ruiz (2011), Urquiza (2017), and others, made it possible to know the main challenges of the reality of indigenous school education. In this sense, it is the intention to do a reflection on the effectiveness of intercultural education, and as it is necessary to continue training, consolidation and strengthening the identity of the traditional people for the construction of the specific and intercultural curriculum.

Key Words: Differentiated school education. Training of indigenous teachers. Curriculum.

Para citar - (ABNT NBR 6023:2018)

MONTEIRO, Alcioni da Silva; MASCARENHAS, Suely Aparecida do Nascimento. Educação escolar diferenciada, formação de professores indígenas e currículo. Eccos - Revista Cientifica, São Paulo, n. 54, p. 1-15, e17338, jul./set. 2020. Disponível em: https://doi.org/10.5585/eccos.n54.17338. 


\section{Introdução}

O estudo sobre a educação intercultural ainda é um processo conflituoso, pois há diferentes discussões acerca da abordagem entre os saberes tradicionais, que devem ser considerados nas aprendizagens da educação escolar diferenciada, e na utilização ideológica e relações da ciência ocidental no campo educacional.

Esses pressupostos implicam e persistem no modo do ser índio, fazendo com que o olhar histórico e social do ser originário do Brasil seja desvalorizado, não reconhecem sua cultura e sua própria identidade, como formas e métodos de conhecimentos, que dialogam entre o currículo intercultural e o currículo ocidental, acolhendo e valorizando assim, as especificidades e diferenças entres os povos indígenas.

Nas discussões da epistemologia dos conhecimentos tradicionais dos índios frente aos meios científicos, realizados no contexto educacional, ocorre a desqualificação e desarticulação dos saberes tradicionais no processo de escolarização mediadas nas escolas não indígenas. Dessa forma, justifica-se neste estudo, as relações e concepções dos professores indígenas acerca do processo e desenvolvimento da educação escolar frente as suas realidades locais.

Essas relações sociais sistematizam os direitos preconizados em lei dos povos tradicionais, como um processo ideológico onde acumula-se e enraíza-se o processo de colonização e desvalorização dos povos. Desde os primórdios da invasão do Brasil, foram estruturadas e implantadas, visões e metodologias, que despiam os índios de suas crenças, valores e cultura.

Como resultado, a educação indígena não foi estruturada para contemplar as necessidades indígenas, mas foi objetivada para a catequização e o massacre cultural. Porém, com a organização dos movimentos e as conquistas dos indígenas por seus direitos, hoje, são estabelecidas em defesa à educação diferenciada., atribuições e deveres constituídos oficialmente em lei.

Desse modo, o currículo deve ser pensado e refletido em uma abordagem inovadora, na qual a interculturalidade é ponderada como uma direção mais concreta e como um campo autônomo. Em seu contexto histórico, a interculturalidade se define como uma direção para a vitalização e revitalização dos saberes tradicionais, atrelados aos conhecimentos científicos para a educação escolar indígena.

A educação intercultural nos fomenta um novo olhar, para uma nova trajetória em relação às práticas pedagógicas dos professores indígenas, emergindo como possibilidade de sistematizar um currículo escolar próprio e diferente do currículo escolar não indígena. Com 
esses pressupostos introduzidos no currículo, concebe-se a reconstrução cultural e o fortalecimento da cidadania dos índios, negados de forma injusta e violenta.

Como é imprescindível efetivar a cultura não inata nas orientações da educação formal e constituir relações diretivas como instrumento de fortalecimento dos saberes tradicionais e identidade dos povos originários do Brasil, o objetivo deste estudo visa analisar a educação diferenciada, formação de professores e currículo, no contexto da Educação escolar Indígena.

Nesse contexto, a formação de professores assume uma desafiadora relevância ao se pensar em um processo de preparação acadêmica que esteja em sintonia com as exigências de uma educação que se presta diferenciada. A construção de um aparado pedagógico para o fortalecimento cultural, tem que ser pensado no currículo como tarefa de valorização e reconhecimento dos saberes tradicionais, bem como do seu papel na efetivação e respeito ao diferenciado das sociedades indígenas e o relacionamento destas com a sociedade nacional.

Para nortear o presente artigo, enfatizou-se como objetivo central a compreensão da Educação diferenciada como projeto político de respeito às diferenças culturais, fundamentadas no princípio da interculturalidade e da representação democrática. Entendendo e direcionando a Educação Escolar diferenciada como proposta pedagógica de fortalecimento e vitalização da identidade indígena, analisando o processo de formação de professores indígenas como princípios norteadores dos valores culturais, da interação intercultural e do currículo enquanto ferramenta necessária e sistemática.

A escolha da presente temática foi motivada por sua demonstrada importância cultural, ao servir como instrumento de conhecimento dos pilares formadores de uma proposta educativa diferenciada. Nesse contexto, vislumbra-se conhecer os processos político-pedagógicos pelos quais e nos quais são estruturadas as políticas educacionais pautadas no respeito às diferenças e à cultura dos povos indígenas.

Os procedimentos metodológicos adotados basearam-se em pesquisa bibliográfica em livros e artigos científicos, com base teórica relevante para as análises desta temática. Conforme Gil (2002, p. 45), “a principal vantagem da pesquisa bibliográfica reside no fato de permitir ao investigador a cobertura de uma gama de fenômenos muito mais ampla do que aquela que poderia pesquisar diretamente".

Desses referenciais foram coletadas informações acentuadas para a compreensão do tema em discussão, à medida que se estabeleceu um diálogo com os autores, possibilitando a construção do presente texto em forma de Artigo de Revisão Bibliográfica. 


\section{A educação escolar indígena como educação escolar diferenciada}

A oferta de educação escolar indígena no Brasil ensaia seus primeiros passos com a chegada dos religiosos, especialmente os integrantes da Companhia de Jesus. Tão logo iniciado, de fato, o processo colonizador com o estreitamento do contato entre índios e não índios, aos poucos, foi surgindo a ideia de uma Educação Escolar Indígena, porém, como necessidade imposta do conhecimento dos valores da cultura branca pelos colonizadores do Brasil.

Cabe ressaltar que cada povo que habitava nas terras conquistadas pelos colonizadores europeus, já possuíam suas formas próprias de educação, que se fomentavam através da oralidade, de geração em geração. Em um contexto multicultural que imperava (e ainda impera) no Brasil pós descobrimento, a educação escolar indígena é imposta aos nativos da terra brasilis, como instrumento de dominação e imposição da cultura ocidental aos milenares costumes e cultura indígena.

Espar (2014, p. 21) ressalta que "com a implantação da escola em terras indígenas, os elementos místicos e centrais da cultura desses povos tradicionais, sofreram amplo e destrutivo processo de discriminação".

Conforme Pérez Ruiz e Villamar (2011), com a exclusão e proibição de seus princípios culturais, os índios do Brasil foram negando, se afastando e esquecendo dos próprios costumes, até chegar à aceitação da escolarização diante das suas particularidades e diferenças sociais. No entanto, o que a classe opressora ocultava dos nativos do Brasil, era o grande objetivo do projeto educativo formal, o qual visava a eliminação da cultura indígena.

Visto como um empecilho ao desenvolvimento do país, durante séculos, os índios foram pensados como pessoas sem almas e sem cultura adequada aos padrões do cristianismo da época. Nessa visão, os povos originários, viveram em transição a uma civilização e assimilação da cultura imposta por outros. Como resultado desse processo ideológico, a dizimação das nações indígenas foi gradual e alastrante, deixando marcas irreversíveis no processo histórico brasileiro.

A escola era a grande arma das massas colonizadoras. Utilizada como ferramenta para alienar e escolarizar o índio, incorporando-os como mão de obra à sociedade brasileira. Ao analisar o impacto devastador da implantação da educação escolar nas aldeias no período colonial, o MEC afirma que 
Quando a escola foi implantada em área indígena, as línguas, a tradição oral, o saber e a arte dos povos indígenas foram discriminados e excluídos da sala de aula. A função da escola era fazer com que estudantes indígenas desaprendessem suas culturas e deixassem de ser indivíduos indígenas. Historicamente, a escola pode ter sido o instrumento de execução de uma política que contribuiu para a extinção de mais de mil línguas (SECAD - MEC. 2007, p. 11).

Macedo (2015, p.43) assinala que nas últimas décadas ocorreu um intenso processo político reivindicatório posto em curso pela sociedade civil organizada e lideranças indígenas, com o objetivo de assegurar "uma escola que considerasse de fato e de direito as especificidades linguísticas e culturais dessas sociedades".

Pensada a partir destes pressupostos, a educação escolar se torna uma ferramenta para as sociedades indígenas defenderem seus direitos junto aos poderes constituídos, além de poderem dialogar de forma construtiva com as diferentes culturas que integram o Estado brasileiro. Dessa forma,

a educação passa a ser considerada pelos indígenas, como espaço estratégico e relevante em seus esforços de melhorar suas condições de inserção, diálogo e de enfrentamento nesses novos territórios, sem abrir mão da afirmação de suas múltiplas identidades e projetos de autonomia (URQUIZA. 2017, p. 54).

A luta trava-se em torno da ideia de criação de uma educação realmente diferenciada aos povos indígenas, que respeitasse suas especificidades culturais e garantisse a perenidade de sua língua e de sua história. Surge assim, no âmbito das lutas e movimentos, por democracia no Brasil e pelo respeito aos diferentes povos e culturas, o conceito de educação diferenciada, como bandeira de ação pelo respeito e garantia da vitalização da cultura indígena.

Grupioni define educação escolar indígena com a seguinte afirmação:

conjunto de práticas e intervenções que decorrem da situação de inserção dos povos indígenas na sociedade nacional, envolvendo agentes, conhecimentos e instituições, até então estranhos à vida indígena, voltados à introdução da escola e do letramento (GRUPIONI. 2000, p. 274).

Esse processo educativo, conforme Espar (2014, p. 43), funda-se "numa ruptura epistemológica, política e ideológica com as pedagogias dominantes". Tem por finalidade principal resgatar a história, a língua e os demais aspectos da cultura de um grupo, aproximando-o do debate político com os demais setores da sociedade nacional. Nesses pressupostos a escola diferenciada é definida da seguinte forma:

é aquela que abriga acolhedoramente, a diferença: aceita-a, analisa-a, reconhece-a. Se a escola é um lugar onde processos locais, regionais, nacionais e globais se entrecruzam, é no conhecimento de saberes também múltiplos, que está a sua força como instrumento indígena (SILVA. 2001, p.16).

Reconhece-se a Constituição Federal de 1988 como marco legal da garantia de uma educação de valorização da cultura indígena, planejada e executada com base nas formas 
próprias da aprendizagem de cada etnia. O projeto constitucional também prevê a utilização de pedagogia própria, que atenda às especificidades de cada etnia.

Para Baniwa, a educação diferenciada representa uma grande conquista no relacionamento dos povos indígenas com os não indígenas e um grande passo na expansão do estado democrático de direito às chamadas minorias culturais. Esta proposta educativa emerge na conjuntura educativa nacional, com a finalidade de ‘

pensar e praticar os processos político-pedagógicos a partir das realidades sóciohistóricas dos distintos povos. São, portanto, escolas com projetos políticopedagógicos próprios, capazes de atenderem às necessidades das comunidades específicas e com autonomia na gestão administrativa, política e pedagógica (BANIWA, 2006, p. 158).

Nesse contexto de reconhecimento do 'outro' como dotado de cultura, mais um termo é levado em conta na literatura especializada quando se trata de educação escolar diferenciada: o de "específico". A utilização desse termo indica que cada povo possui sua própria cultura, sua própria história, formas próprias de aprender e de ensinar, que vai demandar um contexto educacional diferenciado para cada povo.

Sobre isso, Espar (2014, p. 44) corrobora também, afirmando que este termo "dá conotação de que cada povo indígena tem uma cosmovisão diferente (ou específica), a partir dela se dá a relação desse povo com a natureza, com a terra, com o outro (índio e não-índio) ". Nessas proposições de conquistas, o Artigo 210 da Constituição de 1988 define a garantia de educação diferenciada para as comunidades indígenas, quando afirma que:

1. Serão fixados conteúdos mínimos para o ensino fundamental, de maneira a assegurar formação básica comum e respeito aos valores culturais e artísticos, nacionais e regionais.

2. O ensino fundamental regular será ministrado em língua portuguesa, assegurada às comunidades indígenas também a utilização de suas línguas maternas e processos próprios de aprendizagem. (BRASIL, 1988).

Essa conquista se deu frente a muitos conflitos ao longo da história. Vale ressaltar que, com o processo de dominação, os índios contraíram muitas doenças e foram inseridos no modelo de processo da produção ocidental. Além de ser desconsideradas suas peculiaridades, os povos tradicionais não acumulavam qualquer riqueza, visto que viviam culturalmente de maneira diferente dos modos progressistas dos europeus.

A apoderação dos direitos indígenas, principalmente no que tange a educação escolar específica, demonstram o fortalecimento e dignidade de um povo que não aceitou o conformismo de uma ideologia de submissão. A fomentação da conquista em leis, representa a resistência da imposição cultural que foi marcada pela opressão tencionada à exploração de vida e da mente humana. 
A aprovação da Constituição de 1988, ocorreu pela maioria dos países latinoamericanos, a Convenção 169 da Organização Internacional do Trabalho (OIT). Considerada um marco internacional na luta por uma educação formal que atendesse às demandas indígenas, a OIT obriga os Estados signatários a assegurar uma educação escolar que respeite e valorize "a condição de diferença cultural e linguística e as formas tradicionais de conhecimento" (TEIXEIRA \& LANA. 2012, p. 10).

Em meio aos conflitos e conquistas dos povos tradicionais, surgiu o conceito de Educação Escolar diferenciada, a qual deve ser ofertada de maneira diversa daquela promovida nos centros urbanos. Portanto, ao que se refere à política educacional específica, a Convenção 169 da OIT considera a educação diferenciada e a formação de professores, os dois grandes pilares da valorização e revitalização da cultura dos povos tradicionais.

No processo de atribuição das responsabilidades públicas para a garantia da educação diferenciada aos povos tradicionais, a Convenção 169 da OIT afirma que:

\footnotetext{
"A autoridade competente deverá assegurar a formação de membros destes povos e a sua participação na formulação e execução de programas de educação, com vistas a transferir progressivamente para esses povos a responsabilidade de realização desses programas, quando for adequado" (CONVENÇÃO DE 169 da OIT. 2011, p. 35).
}

A Lei de Diretrizes e bases da Educação Nacional (Lei 9.394/96) surge nos anos 1990 para reforçar ainda, o disposto da Carta Constitucional de 1988, estabelecendo a oferta de uma educação escolar indígena com base em uma proposta intercultural e bilíngue.

Essas bases sólidas oportunizaram de maneira sólida, a garantia da não descaracterização dos costumes, tradições e culturas dos povos nativos. E para fortalecer esse contexto, emerge também o currículo intercultural, no qual, transcende as relações sistematizadas entre índios e não índios.

Espar (2014, p. 27) reforça que a "LDB é o primeiro documento que trata de um currículo diferenciado e estabelece o diálogo entre os saberes tradicionais e os saberes universais, colocando a interculturalidade como eixo central do currículo".

Passadas mais de duas décadas do reconhecimento desse direito à nação indígena, percebe-se que na prática, ainda impera uma série de obstáculos para a implantação de uma educação específica e diferenciada a cada povo originário. Há em curso a necessidade de articulação entre os diversos setores nos três níveis da administração, que possam viabilizar a implantação de políticas públicas de expansão da oferta deste modelo educativo.

Dentre os desafios para a expansão da Educação Escolar Indígena Diferenciada e Específica, SECAD - MEC apontam a necessidade de 
i) preencher de sentido o que preceitua a LDB quando estabelece a necessidade do regime de colaboração entre as três esferas administrativas (municipal, estadual e federal) para o pleno desenvolvimento da educação junto às comunidades indígenas; ii) fortalecer e promover a participação indígena na formulação, implementação e avaliação das políticas em curso; iii) garantir a formação de pelo menos 4.000 professores indígenas em cursos de Licenciatura Intercultural nos próximos quatro anos; iv) incrementar a produção de livros, publicações de referência, DVD e CD de autoria indígena, para uso nas escolas e fortalecimento dos currículos diferenciados; v) consolidar o apoio financeiro aos sistemas de ensino para construção, reforma, ampliação e equipamentos de cerca de 2.000 escolas nas aldeias; e, vi) implantar o segundo segmento do Ensino Fundamental e o Ensino Médio em escolas indígenas articulados com a formação profissional dos jovens indígenas em articulação com os projetos societários de futuro de cada povo (SECAD - MEC. 2007, p. 36).

Para que essas situações sejam consideradas e solucionadas, é preciso resistência e organização dos povos. Assim, os ataques a essa nação serão minimizados e a ideologia dominante será percebida e desconstruída, na lógica de que todos somos igualitários conforme os preceitos das leis e cidadãos específicos de uma mesma nação.

\section{A formação de professores no âmbito da educação diferenciada}

Juntamente com as problemáticas já citadas, uma das consolidações norteadas para a garantia da educação escolar indígena, é a formação dos professores indígenas. Todavia, não se pode esquecer que essa compreensão para a garantia da qualidade da escola indígena, cabe ao compromisso dos governantes, com inserções de políticas públicas adequadas às especificidades dos povos, resistência dos movimentos e compromisso dos professores indígenas no fortalecimento da identidade e ressignificação das propostas pedagógicas, com base na cultura e saberes tradicionais das comunidades e aldeias com a qual mediam a educação formal.

Atualmente, a educação escolar indígena diferenciada, enfrenta enormes desafios para se efetivar no cenário geográfico e cultural da maioria das comunidades indígenas. Como afirmam Teixeira \& Lana (2012, p. 132) pelo Brasil afora percebe-se diversos exemplos de governos que implementam políticas públicas contrariando "a realidade sociocultural dos povos indígenas, representando um verdadeiro retrocesso no processo de luta indígena por uma educação diferenciada e bilíngue".

No entanto, os desafios desta proposta educativa não param por aí, visto que não basta apenas condições físicas adequadas para o seu devido funcionamento, como prédio, carteiras, material didático e luz elétrica, por exemplo, mas carecem, sobretudo, de profissionais da educação, de preferência das próprias comunidades indígenas, com formação adequada para atender de forma integral, as demandas das sociedades indígenas, além, é claro, da utilização de uma proposta curricular construída para atender às exigências de cada povo originário. 
A formação de professores indígenas deve ser gerenciada com base na educação escolar indígena diferenciada e que atenda aos interesses e direitos dos índios que vivem nas comunidades tradicionais. Com isso, conforme Urquiza (2017) além de dar um importante passo para a preservação da cultura indígena, evitando mais descaracterização culturais, cria-se a possibilidade de diálogo com os conhecimentos cientificamente produzidos pela sociedade nacional e internacional.

A convenção 169 da OIT tece importantes orientações quanto à formação de professores para atuar na educação formal a ser assegurada aos povos indígenas. Esse documento preconiza a importância de

identificar que a importância da formação de professores indígenas e da oferta de um programa específico de formação de professores para cada povo diz respeito tanto ao fundamento do direito à educação diferenciada nos termos do Convênio 169, que é o de gerir o próprio futuro, como aos princípios de participação e ao objetivo de transferir aos povos interessados a responsabilidade pela realização dos programas de educação (TEIXEIRA \& LANA, 2012, p. 125).

Cabe acrescentar que a formação do professor indígena se reveste de importante ferramenta de enfrentamento dos desafios políticos propostos pela sociedade nacional, e que em muitos casos provoca impactos negativos na cultura indígena das diferentes etnias. Contrariamente a esta proposta de educação formal é relatado,

[...] uma estrutura escolar que não está organizada para a compreensão e respeito às diferenças culturais, além de não permitir o alcance desse objetivo, afasta os indivíduos da vida comunitária que fortalece seu pertencimento étnico (SECAD MEC. 2007, p. 42).

Foi no âmbito do discurso da vitalização e fortalecimento das culturas indígenas, nos termos da responsabilidade pública em assegurar a Educação diferenciada aos povos nativos, que o Governo Federal, através do Secad/MEC desenvolveu o Projeto de Formação de Professores Indígenas para o Magistério Intercultural. Conforme Secad o projeto tem por Objetivo Geral:

Garantir a efetivação do direito dos povos indígenas à educação escolar intercultural de qualidade por meio da formação inicial e continuada de professores, considerando a multiculturalidade e questões sociolinguísticas (SECAD - MEC. 2007, p. 42).

O Projeto segundo SECAD-MEC (2007), vem sendo implementado por meio do apoio a programas voltados à formação continuada de professores para o magistério indígena; fomentação a elaboração de material didático, com a participação de membros das comunidades em consonância com as realidades culturais de cada grupo tradicional e apoio técnico e financeiro às Secretarias de Educação para a criação de seus próprios programas correlatos. 
A formação de professores para o magistério indígena, de forma a assegurar os interesses sociais e culturais desses povos, deve levar em conta questões centrais, tais como a interculturalidade e a adoção de um percurso metodológico peculiar às culturas indígenas.

Na concepção de Aguilera,

Os princípios da proposta intercultural são aqui percebidos como ferramentas pedagógicas para construção da possibilidade de diálogo entre os saberes cientificamente produzidos. Assim, concebemos a possibilidade da interculturalidade, de decolonizar (URQUIZA. 2017, p. 50)

Decolonizar conforme Urquiza (2017), refere-se às estruturais sociais políticas e a visão de mundo impostas pelos agentes da colonização. Todavia essa proposta não é uma tarefa fácil, principalmente com a pressão do Estado para o cumprimento dos fomentos do processo educacional e sem a compreensão de muitos que, os princípios pedagógicos dos povos tradicionais, deve ter como base, seus fundamentos próprios de aprendizagem.

Partindo dessas premissas, Urquiza (2017) afirma que o discurso intercultural possui a função de aproximar intencionalmente as diferentes culturas, promovendo um diálogo baseado no respeito mútuo e na troca de saberes e experiências entre as partes. Por outro lado, pode-se problematizar, o eurocentrismo e o discurso ideológico que ainda se encontra inserido nas falas, nas ações e até mesmo em muitos projetos governamentais da sociedade pós-industrial.

Ainda, conforme Urquiza (2017), esses pressupostos, promovem a articulação entre as diferentes culturas em seus diferentes espaços. Por outro lado, tem o papel de levar os sujeitos em formação a pôr em discussão os ditames dominantes, que durante muito tempo consideram a cultura indígena como sendo inferior e sem função no processo de construção da sociedade nacional.

Em um processo de formação de professores indígenas para a educação intercultural junto aos povos nativos, o posicionamento intercultural vai permitir um novo posicionamento metodológico dos sujeitos envolvidos, qual seja o de enxergar o Outro como dotado de cultura e de capacidade de transformar o mundo.

Nesse processo, a interculturalidade tem o papel de desfazer muitos preconceitos construídos no contexto do processo colonizador, e ainda bastante em voga nos meios, social, educacional e político. Para Urquiza (2017, pp. 63-64) o processo de formação intercultural de professores deve primar pôr "busca pela consolidação de direitos e valores de cidadania em consonância com o ordenamento jurídico vigente, fruto de movimentos e protagonismos reivindicatórios das comunidades indígenas". 


\section{O currículo como pilar da educação diferenciada}

Nas últimas décadas a temática curricular tem sido debatida por diversos estudiosos da Educação, tais como Ghedin (2007) e Macedo (2015), que dentre outros aspectos discutidos, procuram embasar o conceito da palavra como um campo de escolhas políticas e culturais, que privilegia uma determinada visão de cultura hegemônica.

Observa-se no presente século, uma série de definições para a palavra currículo, indo desde às mais práticas e tradicionais àquelas que partem da função curricular na Educação nos dias atuais. No entanto, Sacristán (1998) adverte que não é possível estabelecer um conceito unicamente válido para a palavra currículo. Nesse sentido, Piletti (2002, p. 52), por exemplo, o define como o "conjunto das matérias ensinadas na escola, ou tudo o que é ensino nas unidades escolares". Macedo (2015, p. 52), por sua vez, o define "como processo de construção cultural, política e de controle de poder" executado pelo grupo dominante em uma sociedade.

Segundo Pérez Ruiz e Villamar (2011), a construção de uma proposta curricular, por si só vai exigir a conjugação de enormes esforços de diversos tipos e interesses políticos e educacionais para a sua consecução. Tarefa maior ainda é a proposta aqui discutida, a produção de um currículo que atenda às demandas da Educação diferenciada e específica à cada povo indígena. Considerando que o currículo é uma espécie de seleção de conhecimentos, Espar (2014, p. 54) considera igualmente importante "saber de onde surgiu esse conhecimento, quem o selecionou e a que grupo pertence".

Considerando que, conforme Moreira (1999, p. 8) "o currículo não é um elemento inocente e neutro de transmissão desinteressada do conhecimento social”, cabe aqui enfatizar a importância da construção de um currículo específico para a Educação diferenciada com a ampla participação dos povos tradicionais. O fato de que a construção de qualquer proposta curricular vai refletir a ideologia do grupo propositor, a participação das lideranças indígenas nesse processo torna-se imprescindível, uma vez que, mais que quaisquer outros sujeitos envolvidos, essas lideranças estão a par das necessidades políticas, culturais e educacionais do povo que representam, sendo, portanto os melhores porta-vozes de tais interesses.

Como processo de construção política, conforme Espar (2014), uma proposta curricular que venha representar as demandas indígenas no relacionamento com a sociedade nacional e entre os diferentes povos, deve assegurar uma estreita interação entre os saberes produzidos pelos originários do Brasil e os conhecimentos cientificamente construídos; entre o projeto de sociedade e a política destinada pelos governos a cada povo indígena. 
Silva (2001 apud PERRELLI. 2008, p. 394) salienta a importância de se colocar "os conhecimentos tradicionais e os científicos lado a lado, uma vez que ambos passam a ser vistos como objetos culturais, que expressam significados social e culturalmente construídos". Essas diretrizes, juntamente com a promoção do diálogo intercultural, ganham grande importância na formulação de uma proposta curricular intercultural, pois contribuem para o respeito à diversidade das culturais indígenas e para um equilibrado relacionamento político entre os demais povos.

O termo intercultural, então, exige mais do que o respeito e o reconhecimento de uma diversidade; ele procura identificar, desnaturalizar e questionar os problemas e conflitos causados nas relações e condições históricas e atuais, da dominação, da exclusão e desigualdade; ele busca a transformação da sociedade numa perspectiva decolonial (ESPAR, 2014, p. 64).

Nesse sentido, percebe-se uma estreita relação entre currículo e interculturalidade, quando se leva em conta a oferta de um paradigma de educação que seja realmente diferenciado e específico a cada povo ou etnia. Construída nesta linha de pensamento, essa proposta curricular vai exigir necessariamente mudanças estruturais na Educação, tais como uma ampla adequação dos livros didáticos à proposta de educação diferenciada e específica. Ainda, um processo de formação de professores que deve ter como estrutura central, os interesses das diversas culturas indígenas.

Nesse campo de desafios, o currículo diferenciado para a educação escolar indígena, entendido como "resultado de um discurso e de uma intencionalidade política" (GHEDIN, 2007, p. 18), deve promover uma educação para o reconhecimento da sua própria identidade e também do outro, ou seja, "o diálogo entre os diferentes grupos socioculturais, valorização da diferença, a construção de uma sociedade democrática, plural, humana, que articule políticas de igualdade com políticas de identidade" (CANDAU, 2008, p. 54).

Todavia, não se pode olvidar que a base de um currículo diferenciado e específico, emerge da sistematização não indígena. De maneira que, a cultura tradicional, histórica e social no que concerne a caracterização de identidade dos povos, deve ser construída em seus pressupostos e características próprias. Levando em consideração a reconstrução necessária da cultura e saberes próprios de cada povo nativo do Brasil.

A interculturalidade emerge como possibilidade desse caminho, onde as relações tradicionais fomentadas de forma pedagógica no currículo escolar, oportunizam-se como um processo de fortalecimento, vitalização, reconstrução e ressignificação de construções fundamentais na promoção de pressupostos educativos para a autonomia da cidadania indígena. 


\section{Considerações finais}

O processo de uma educação escolar indígena diferenciada e intercultural que ansiamos neste estudo, pode ser entendida como uma proposta de consolidação da cidadania e direito da diversidade dos povos brasileiros. Contudo, é necessário destacar a perspectiva como paradigma diferenciado para a educação formal dos originários do Brasil, que se anuncia no sentido de respeitar e responder às especificidades culturais dos diferentes povos indígenas.

Com a ideia de integração e superação, resultante das resistências, espera-se que seja concretizado na prática, o respeito à diferença e aos objetivos daqueles povos que tanto foram oprimidos e massacrados; para o fortalecimento de seus saberes tradicionais, formas como lidam com a natureza e com o mundo. Assim, a formação dos professores indígenas emergirá como um correspondente primordial para a efetividade e respeito dos povos nativos a uma educação escolar diferenciada e intercultural.

Com a consonância desses pressupostos, a educação diferenciada enquanto paradigma educacional, é a forma concreta do resgate e promoção do respeito e estudo das culturas dos originários do Brasil. Enquanto política pública, é o fomento sinalizador para a construção de uma sociedade onde prevaleça o respeito às diferenças e o progresso dos princípios democráticos em todas as instancias sociais.

Dado o gigantismo da ideia imbuída neste projeto de sociedade, os desafios que competem aos entes públicos e privados responsáveis, revestem-se das mesmas dimensões, criando, assim, a necessidade de formulação de várias políticas públicas, capazes de ampliar a oferta de formação para professores bilíngues e a promoção ao debate curricular que viabilize esta proposta educativa.

Em uma sociedade que se pretende democrática, especialmente a brasileira, onde praticamente inexiste o respeito às diferenças e impera em grande medida o preconceito e o silenciamento dos povos indígenas e grupos socialmente excluídos, torna-se imprescindível um amplo e complexo processo de educação ou ressignificação de valores não ideológicos. Talvez assim, seja desconstruída de fato, a educação de transgressão aos valores impostos pelos opressores. 


\section{Referências}

BANIWA, G. (2006). O Índio Brasileiro: o que você precisa saber sobre os povos indígenas no Brasil de hoje. Coleção Educação Para Todos. Brasília.

BRASIL (1988). Constituição da República Federativa do Brasil: texto constitucional promulgado em 5 de outubro de 1988, com as alterações determinadas pelas Emendas Constitucionais de Revisão nos 1 a 6/94, pelas Emendas Constitucionais nos 1/92 a 99/2017 e pelo Decreto Legislativo no 186/2008. - Brasília: Senado Federal, Coordenação de Edições Técnicas.

BRASIL. (2018). LDB: Lei de diretrizes e bases da educação nacional. - 2. ed. - Brasília: Senado Federal, Coordenação de Edições Técnicas. [Disponível em https://www.senado.leg.br>handle, consultado em 21/07/2019].

CANDAU, V. M. (2008). Direitos humanos, educação e interculturalidade: as tensões entre igualdade e diferença. Revista Brasileira de Educação v. 13 n. 37 jan./abr.

Convenção $n^{\circ} 169$ sobre povos indígenas e tribais e Resolução referente à ação da OIT (2011). Organização Internacional do Trabalho. - Brasília: OIT, 2011 v. ISBN: 978-92-2824257-7 (print); 978-92-2-824258-4 (web pdf).

ESPAR, V. T. da H. (2014). Processo de Estadualização da Educação Escolar Indígena e Desafios para um Currículo Intercultural (Dissertação de Mestrado. Universidade Federal De Pernambuco. Recife.

GIL, A. C. (2002). Como elabora Projetos de Pesquisa. 4ª ed. São Paulo: Atlas.

GHEDIN, Evandro (2007). Teorias do currículo. In: GHEDIN, Evandro (org.) Currículo: Avaliação e gestão por projetos no ensino médio. $2^{\mathrm{a}}$ ed. Manaus: Editora Travessia/SEDUC.

GRUPIONI, L. D. B. (2000). Contextualizando o campo da formação de professores indígenas no Brasil. In: GRUPIONI, Luiz Donizete Benzi. Brasília (org.). Formação de professores indígenas: repensando trajetórias. Ministério da Educação, Secretaria de Educação Continuada, Alfabetizada e Diversidade.

SILVA, A. L. da (2001). Educação para a tolerância e os povos indígenas no Brasil. In: Povos Indígenas e Tolerância: Construindo práticas de respeito e solidariedade. São Paulo: Editora da Universidade de São Paulo.

MACEDO, A. S. (2015). Saberes Tradicionais Krahô e Educação Escolar Indígena: Um Diálogo Possível na Escola Indígena. 19 de abril, Araguaina. Dissertação de Mestrado em Ensino de Língua e Literatura. Brasil: Universidade Federal de Tocantins.

MOREIRA, A. F. B. \& DA SILVA, T. T. (1999). Sociologia e Teoria Crítica do Currículo: uma introdução. In:.Currículo, Cultura e Sociedade. 3. ed. São Paulo: Cortez.

PILETTI, C. (2002). Didática Geral. 23ª ed. São Paulo: Editora Ática. 
PÉREZ RUIZ, Maya Lorena y VILLAMAR, Arturo Argueta (2011). “Saberes indígenas y diálogo intercultural”. En Cultura y Representaciones Sociales, año 5, núm. 10, pp. 31-56. México, IIS-UNAM.

PERRELlI, M. A. de S. (2008). "Conhecimento Tradicional" e Currículo Multicultural: Notas com base em uma experiência com estudantes Indígenas Kaiowá/Guarani. Ciência \& Educação, v. 14, n. 3, p. 381-96.

SACRISTÁN, J. G. (1998). Compreender e transformar o ensino. $4^{\circ}$ ed. Porto Alegre: ArtMed.

SECAD-MEC. (2007). Secretaria de Educação Continuada, Alfabetização e DiversidadeMinistério da Educação Cadernos Secad. Educação Escolar Indígena: diversidade sociocultural indígena ressignificando a escola. Brasília-DF. Disponível em:

http://portal.mec.gov.br/secad/arquivos/pdf/educacaoindigena.pdf Acesso em: 27/09/2019.

TEIXEIRA, V. C. G. \& LANA, E. dos S. C. (2012). Interculturalidade e Direito Indígena à Educação - A Política Pública de Formação Intercultural de Professores Indígenas do Brasil.

URQUIZA, A. (2017). A Interculturalidade como ferramenta para descolonizar a educaçãoReflexões a partir da ação 'Saberes Indígenas na Escola. Articul. constr. saber., Goiânia, v.2. 